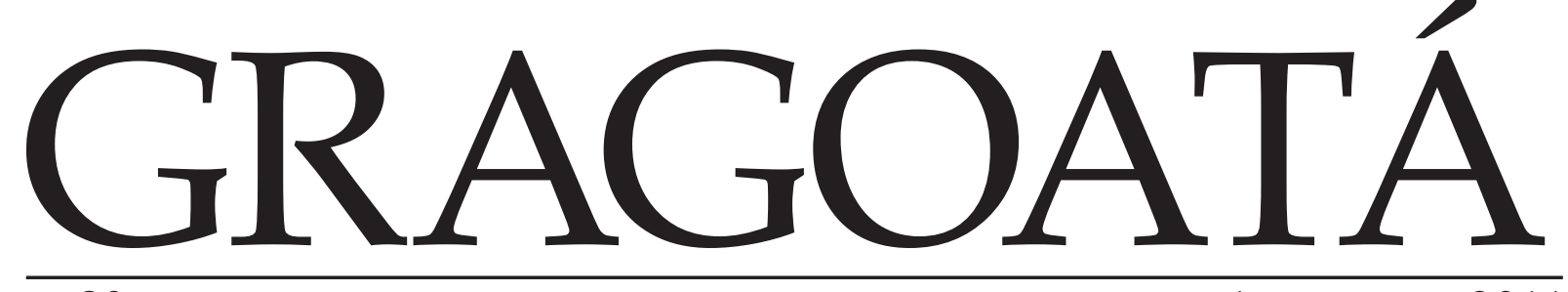

\title{
Política Editorial
}

A Revista Gragoatá tem como objetivo a divulgação nacional e internacional de ensaios inéditos, de traduções de ensaios e resenhas de obras que representem contribuições relevantes tanto para reflexão teórica mais ampla quanto para a análise de questões, procedimentos e métodos específicos nas áreas de Língua e Literatura.

ISSN 1413-9073 
Programas de Pós-Graduação do Instituto de Letras da Universidade Federal Fluminense Direitos desta edição reservados à- Editora da UFF - Rua Miguel de Frias, 9 - anexo - sobreloja - Icaraí - Niterói - RJ - CEP 24220-900 - Tel.: (21) 2629-5287 - Telefax: (21)2629-5288 http://www.editora.uff.br - E-mail: secretaria@editora.uff.br

Organização:

Projeto gráfico:

Capa:

Diagramação e supervisão gráfica:

Coordenação editorial:

Periodicidade:

Tiragem:
É proibida a reprodução total ou parcial desta obra sem autorização expressa da Editora.

Jussara Abraçado e Eduardo Kenedy

Estilo \& Design Editoração Eletrônica Ltda. ME

Rogério Martins

Káthia M. P. Macedo

Ricardo Borges

Semestral

400 exemplares
Dados Internacionais de Catalogação na Publicação

G737 Gragoatá. Publicação dos Programas de Pós-Graduação do Instituto de Letras da Universidade Federal Fluminense.- n. 1 (1996) - . - Niterói : EdUFF, 2010 $26 \mathrm{~cm}$; il.

1. Literatura. 2. Linguística.I. Universidade Federal Fluminense. Programas de

\section{Reitor:}

Vice-Reitor:

Pró-Reitor de Pesquisa e Pós-Graduação: Diretor da EdUFF:

Conselho Editorial:
Conselho Consultivo:
Organização: Jussara Abraçado e Eduardo Kenedy

Semestral

ISSN 1413-9073 Pós-Graduação em Estudos de Linguagem e Estudos de Literatura.

CDD 800

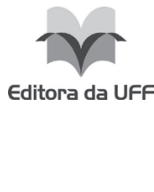

Roberto de Souza Salles

Sidney Luiz de Matos Mello

Antonio Claudio Lucas da Nóbrega

Mauro Romero Leal Passos

Mariangela Rios de Oliveira - UFF - Presidente Maria Lúcia Wiltshire - UFF

Fernando Muniz - UFF

Jussara Abraçado - UFF

Vanise Medeiros - UFF

Maria Elizabeth Chaves - UFF

Mônica Savedra - UFF

Paula Glenadel - UFF

Silvio Renato Jorge - UFF

Xoán Lagares - UFF

Arnaldo Cortina - UNESP/ARAR

Dermeval da Hora - UFPB

Eneida Leal Cunha - UFBA

Eneida Maria de Souza - UFMG

Erotilde Goreti Pezatti - UNESP/SJRP

Jacqueline Penjon - Paris III- Sorbonne Nouvelle

José Luiz Fiorin - USP

Leila Bárbara - PUC/SP

Mabel Moraña - Saint Louis University

Márcia Maria Valle Arbex - UFMG

Marcos Antônio Siscar - UNICAMP

Marcus Maia - UFRJ

Margarida Calafate Ribeiro -

Univ. de Coimbra

Maria Angélica Furtado da Cunha UFRN

Maria Eugênia Lamoglia Duarte - UFRJ

Regina Zilberman - UFRGS

Roger Chartier - Collège de France

Vera Menezes - UFMG

Sírio Possenti - UNICAMP

Teresa Cristina Cerdeira - UFRJ

Ana Pizarro (Univ. de Santiago do Chile)

Maria Luiza Braga (UFRJ)

Cleonice Berardinelli (UFRJ)

Célia Pedrosa (UFF)

Eurídice Figueiredo (UFF)

Evanildo Bechara (UERJ)

Hélder Macedo (King's College)

Laura Padilha (UFF)

Lourenço de Rosário (Fundo Bibliográfico de

Língua Portuguesa)

Lucia Teixeira (UFF)

Marlene Correia (UFRJ)

Michel Laban (Univ. de Paris III)

Mieke Bal (Univ. de Amsterdã)

Nádia Battela Gotlib (USP)

Nélson H. Vieira (Univ. de Brown)

Ria Lemaire (Univ. de Poitiers)

Silviano Santiago (UFF)

Teun van Dijk (Univ. de Amsterdã)

Vilma Arêas (UNICAMP)

Malcolm Coulthard (Univ. de Birmingham) 